\title{
Health Education for Chronic Obstructive Pulmonary Disease (COPD): Observational Study
}

\author{
Leigiane Alves Cardoso ${ }^{1 *}$, Roberta Lins Gonçalves², Fernanda Figuerôa Sanches ${ }^{2}$, \\ Maria do Socorro Lucena Cardoso ${ }^{2}$, Wilson de Souza Nogueira², Edson de Oliveira Andrade², \\ Erik Coelho da Costa ${ }^{3}$, Denilsi Gomes Gonçalves ${ }^{4}$, Jaqueline de Sousa Veras Barbosa ${ }^{4}$, \\ Lucas Normando da Silva ${ }^{4}$, Elvis Geanderson Lima do Vale ${ }^{5}$
}

\footnotetext{
${ }^{1}$ Postgraduate Program in Communication Sciences (PPGCCOM-UFAM), Manaus, Brazil

${ }^{2}$ The Federal University of Amazonas (UFAM), Manaus, Brazil

${ }^{3}$ Neonatal Intensive Care, The Federal University of Amazonas (UFAM), Manaus, Brazil

${ }^{4}$ The Strictu Sensu Postgraduate Program in Health Sciences (PPGCIS-UFAM), Manaus, Brazil

${ }^{5}$ Graduating in Physical Education, The Federal University of Amazonas (UFAM), Manaus, Brazil

Email: *leigianecardoso@gmail.com
}

How to cite this paper: Cardoso, L.A., Gonçalves, R.L., Sanches, F.F., do Socorro Lucena Cardoso, M., de Souza Nogueira, W., de Oliveira Andrade, E., da Costa, E.C., Gonçalves, D.G., de Sousa Veras Barbosa, J., da Silva, L.N. and do Vale, E.G.L. (2020) Health Education for Chronic Obstructive Pulmonary Disease (COPD): Observational Study. Open Journal of Therapy and Rehabilitation, 8, 60-71.

https://doi.org/10.4236/ojtr.2020.83006

Received: April 11, 2020

Accepted: July 29, 2020

Published: July 30, 2020

Copyright $\odot 2020$ by author(s) and Scientific Research Publishing Inc. This work is licensed under the Creative Commons Attribution International License (CC BY 4.0).

http://creativecommons.org/licenses/by/4.0/

(c) (i) Open Access

\begin{abstract}
Health Education has shown itself as essential for the understanding of individuals about psychological and physical changes caused by diseases. The chronic obstructive pulmonary disease (COPD) is a severe public health problem, and it depends on health education measures for its control. A group of patients with COPD, in pneumatological medical treatment, were investigated to find information about the disease. An observational, descriptive and analytical study with analysis and application of a semistructured questionnaire to evaluate the individuals' knowledge about the COPD. Collected data were registered and analyzed using Google Docs. The software used for the calculation of statistical measures was Microsoft Excel ${ }^{\oplus}$. For the research participants' characterization analysis, the use of grouped data for the frequency distribution of Sturges Rule was necessary. This study provided knowledge about which information a group of bearers of COPD receives at a college hospital providing treatment. The interviewed have an average age of 70 years old and most are women with education level between elementary and high school and diagnose time of 6.8 years. Most of the sample reported knowledge and consciousness about the disease, informed by the doctors, followed by physiotherapists. Although the role of the Ministry of Health in health education, subjects were better informed about the disease by their doctors instead of public campaigns.
\end{abstract}




\section{Keywords}

COPD, Health, Education, Pulmonary Rehabilitation, Communicational Ecosystems

\section{Introduction}

Chronic obstructive pulmonary disease (COPD) is a severe problem of public health. According to the project Global Initiative for Chronic Obstructive Lung Disease GOLD, a global initiative that started activities in 1998 for diagnosing, handle and prevention of COPD, the disease is considered common, preventable and treatable. it is distinguished by chronic obstruction of the airflow, progressive and not entirely reversible, associated by an abnormal inflammatory response of the lungs to the inhalation of particles and toxic gases, besides other risk factors like environmental pollution, poor socioeconomic condition and childhood grave respiratory infections, being smoking one of the main risk factors of the disease [1] [2] [3].

COPD has no cure and is associated with frequent exacerbations, which requires many hospitalizations and causes a great assistance load [4] [5]. It is the most costly respiratory disease to the Unique Health System (SUS). It is estimated that the cost of hospitalizations represents between $40 \%-57 \%$ of the total direct costs generated by these individuals, reaching $63 \%$ in severe cases. Despite the alarming data, the impact of COPD is sometimes underestimated because the pathology is not usually recognized and diagnosed until it is clinically evident and an advanced stage. This, many individuals have never heard anything about this [4]. An education component in the management of chronically diseased individuals care has a fundamental role in that health help and may minimize the disease impact [5]. Strategies to raise access to information by the population about the disease and the management of their health risk factors, care, and other components make themselves an important approach to Health Education [4] [5].

In Brazil, The Ministry of Health (2014), is responsible for the organization and elaboration of plans and public policies facing promotion, prevention, and help to national health [6] [7]. In this way, the Ministry of Health must include health education in its strategies [8] [9]. However, according to the ministry, the exercise of health education must involve 3 segments of priority players: health professionals, reinforcing the prevention measures and health promotion the same way as the curative practices, informing their patients all about the disease and their health, empowering them about the care. Managers behind the health professionals and the population who need to build up knowledge and raise the autonomy in the individual and collective care [9]. It's possible that in Brazil these strategies present a great distance between rhetoric and practice, and can't cover important health chronic conditions, like COPD. 
Thus, the study guiding question was: Are a group of individuals with COPD under pneumatological treatment receiving information about their illness? This group was analyzed about the knowledge of the main causes of the disease, how was the treatment; how they were receiving info about the disease and who gave that information.

\section{Methods}

\subsection{Project and Evaluation Sample}

An observational study, transversal, accomplished on Araújo Lima Ambulatory, HUGV/UFAM, Manaus/AM, using a convenience sample, composed 75 COPD diagnosed patients. This number referred to all participants interviewed on-site and via phone attending the criteria of inclusion and exclusion. Inclusion criteria: patients above 18 years old who presented clinical diagnostic of COPD. Were part out of this patients' medical care through elective consultations, and already included in the pulmonary rehabilitation program. Exclusion criteria: patients who have no cognitive condition to comprehend and answer the questionnaire and those who presented the COPD diagnose for less than 1 year. In addition to during the questionnaire confirm the use of cigarettes after diagnosis.

\subsection{Collection Instrument}

The present study was approved by the Comitê de Ética em Pesquisas (CEP) at the Federal University of Amazonas (UFAM), CAAE: 92518318.8.0000.5020, by the document number: 2.928.217 following all the ethical rules for studies in humans. A semi-structured questionnaire created by the researchers was applied, based on the Hospital Saint George for Respiratory Disease (SGRQ) questionnaire by Jardim et al., for individuals with COPD on Brazil, containing questions about the knowledge patients have about the disease and who gave this information. The data collected were variables like personal data: name, age, gender, profession, academic degree and sick time (years), besides questions about knowledge of the disease.

\section{Statistical Analysis}

The collected data were registered on Google Docs. The data analysis was done on Microsoft Excel, mainly to statistical calculation. For the research participants' characterization analysis, a group data frequency distribution was used. The number of classes was obtained using the Sturges Formula (seven classes). From this distribution, a histogram was built for representation and calculated the measure of the central tendency (average, mode, and median) and the separatrixes (quarts). For the other variables related to the investigation about COPD, we used Google Docs graphics for analysis, for the answers of the questionnaire were the yes/no type.

\section{Results and Discussion}

This study has provided information about the level of knowledge of a group with 
COPD, that was undergoing medical treatment at a university hospital based in Manaus, had about COPD and where this knowledge was acquired. The sample had the number of 75 individuals with an average age of 70 years, and it was observed that $22.67 \%$ of the sample belonged to the age group between 55 and 65 years and $29.33 \%$ was between 75 and 85 years, the data referring to age are shown in Graphic 1, mostly women, with basic and secondary education, as shown in Graphic 2, and with an average time of diagnosis of the disease of 6.8 years.

Most individuals in the sample reported having acquired knowledge and a certain sense about the disease, through information provided first by doctors, then by physiotherapists. It was also known that after the information type was acquired from doctors, TV and radio were the means of communication in which the participants most declared to receive information about COPD, followed by the internet. Campaigns and booklets were declared by a small portion of the sample, as shown in Graphic 3 and Figure 1. Most declared to receive information and guidance on how to live life in a healthier way.

COPD is a complex disease, which requires a lot of care, and has to be managed by a multidisciplinary team, with integrated treatment programs. Humanized reception is recommended, highlighting the role of health education, with guidance on the disease, treatment and reduction of predisposing factors [1] [10] [11]. Pharmacological therapy for COPD is used to reduce symptoms, control the frequency

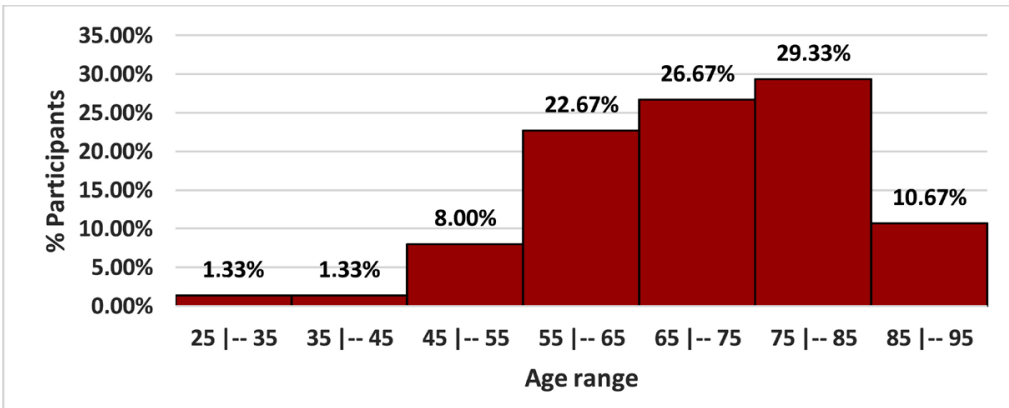

S: The number of 75 individuals with an average age of 70 years; observed that $22.67 \%$ of the sample belonged to the age group between 55 and 65 years and 29.33\%; was between 75 and 85 years. According to the education level, $42.7 \%$ presented complete primary education, followed by $34.7 \%$ that completed high school.

Graphic 1. Sample distribution according to the age, median and quartiles frequency (Qi).

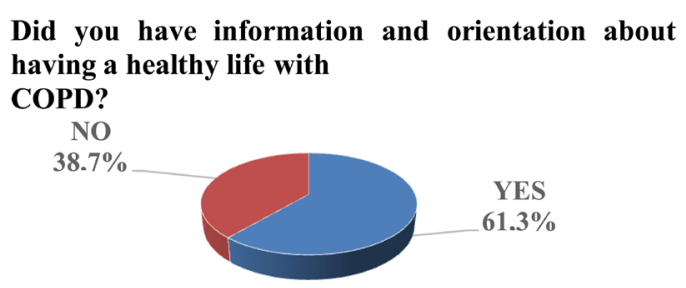

Graphic 2. Percentage of research participants with COPD. 
and severity of exacerbations, in addition to improving exercise tolerance and health. However, despite the essentiality of pharmacology in the treatment of COPD, there are other adjuvant resources [1]. Our results, suggest that the line of treatment adopted for the research participants, probably, is medical-pharmacological centered, since most patients believed, that there is treatment for COPD, and all declared that this treatment it is medicated, as observed in Graphic 4 and Graphic 5.

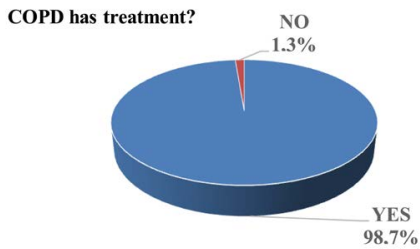

S: The information about disease $61.3 \%$ acquired knowledge and a certain healthy life; This information provided first by doctors $95.50 \%$, then by physiotherapists $42.40 \%$ receive information COPD.

Graphic 3. Percentage of research participants with COPD.

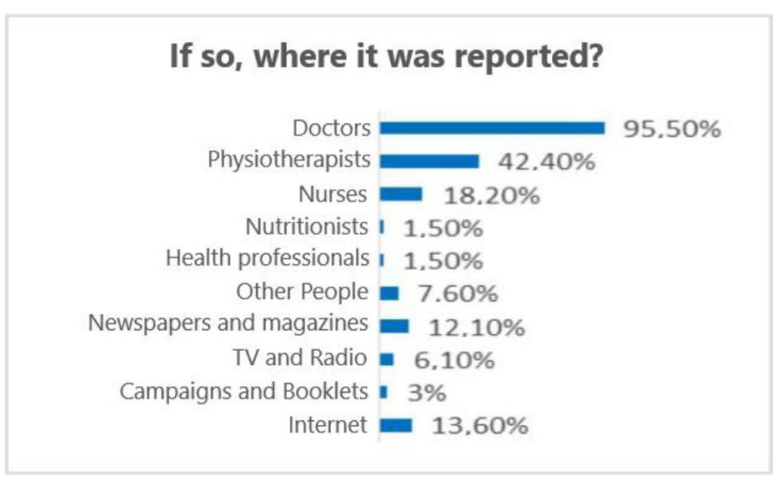

Figure 1. Percentage of the sample COPD information.

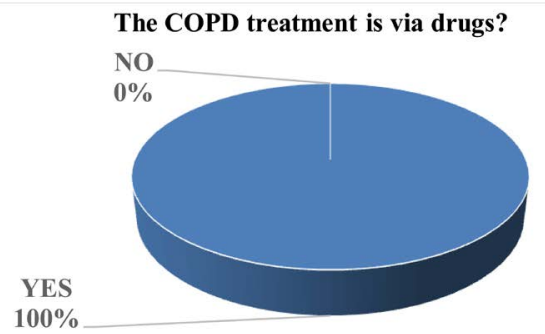

S: The participants declared $98.7 \%$ treatment adopted; all declared $100 \%$ that treatment it is medicated.

Graphic 4. Percentage of research participants with COPD.

Being a smoker/ex-smoker is a factor that causes COPD?

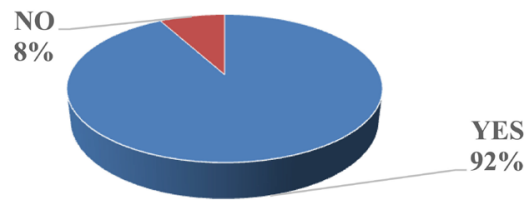

Graphic 5. Percentage of research participants with COPD. 
Generating an Action Plan would help to identify practical ways to educate the public about COPD. To reach a great impact on the multiple factors that interfere in the health-disease process, it is essential that the care for these patients is conducted by a multidisciplinary and interdisciplinary team, in order to improve prevention, diagnosis and treatment [11] [12]. Smoking is the most commonly found risk factor and easily identifiable as a risk of developing COPD [1] [13]. On Gold's recommendation, interrupting the praxis of smoke is considered the fundamental intervention for COPD patients who smoke. In Graphic 6 and Graphic 7, we observed that our results showed that most interviewees reported having knowledge about this subject and considered that being a smoker or a former smoker is a factor that causes COPD. However, most did not know that living with a smoker is a factor that can also predispose the individual to present with COPD [1] [12] [13].

Regarding the importance of vaccination, most respondents are related to the knowledge of this information, based on Graphic 8 and Figure 2. COPD patients contract recurrent bacterial and viral infections, it makes that population relatively immune deficient compared to healthy people [14]. Therefore, annual influenza vaccination has become universally recommended in the COPD guidelines [15]. Besides reducing serious diseases such as respiratory tract infections, anti-influenza and anti-pneumococcal vaccination reduces the likelihood of exacerbations of COPD [1]. COPD patients who were vaccinated against influenza showed a 52\% reduction in hospitalizations and a 70\% mortality rate [16].

\section{Continue smoking or living with someone that smoke causes or worsen the COPD?}

YES

NO

$62.7 \%$

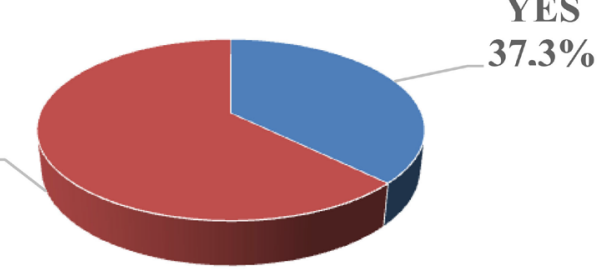

S: The results $92 \%$ showed that most interviewees reported having knowledge about a smoker is a factor that causes COPD; most participants $62.7 \%$ did not know that living with a smoker causes or worsen the COPD.

Graphic 6. Percentage of research participants with COPD.

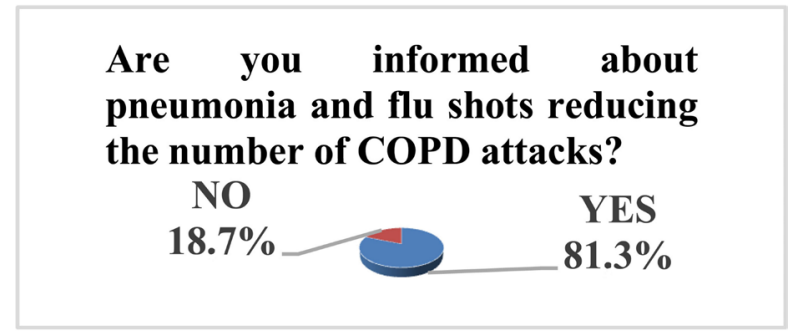

Graphic 7. Percentage of research participants with COPD. 


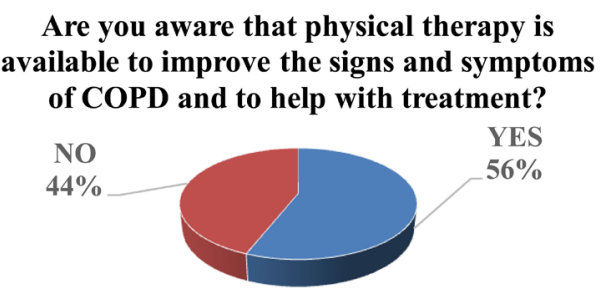

S: The importance of vaccination, $81.3 \%$ most respondents are related to the knowledge of this information; Most participants $68.30 \%$ related informed by doctors about vaccination.

Graphic 8. Percentage of research participants with COPD.

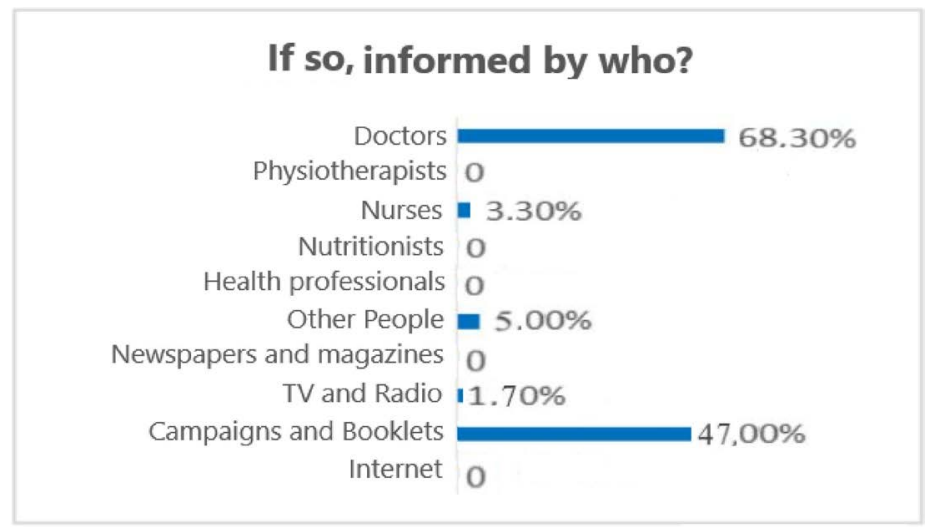

Figure 2. Percentage of the sample about COPD information.

Pulmonary Rehabilitation (PR) is considered one of the most important nonpharmacological treatments for COPD, because comprise both the chronic and progressive characteristics of this disease [16]. However, according to Graphic 9 and Figure 3, only $56 \%$ of the participants declared knowledge of this benefit. Combined interventions for the management of COPD include: behavior modification, such as interrupting the praxis of smoke and physical exercise, psychological support, education of the patient regarding his disease and health, and psychosocial assistance, aiming to maintain the maximum level of independence and its functional capacity before society [17] [18]. PR is an important part of the clinical management of COPD, from it can manage exacerbations, improve the perception of symptoms, exercise capacity and quality of life for individuals [18] [19] [20] [21] [22]. In addition, it is argued that PR generates positive psychological changes, characterized by improved functional skills and increased motivation related to life [13].

The medical society has been making a wide dissemination of COPD in the media [23] [24]. Our results showed that medical professionals were the ones who most offered information to patients. However, Graphic 10 shows that the majority of the sample stated that they had not received information through the media, and of those who did, most were on TV or radio, followed by the internet, declaring little information received through booklets and campaigns according Figure 4.

The increase in access to health information online, the role of the internet has grown as a means of communication. It can provide opportunities for the use of 
information and communication technologies in a manner applied to patient education. However, it is important that this information is organized by the Ministry of Health, due to the risk of wrong or adverse information. Therefore, in a systematic and planned way, all technologies are seen positively in the contribution to health education [19] [20]. Cyberspace allows access to information at a level considerably higher than that allowed by any other communication environment and also influences the political life of society through the creation of a new form of participation in the public space, cyber democracy [25] [26].

\section{Did you receive information about the importance of feeding and nutrition for COPD patients?}

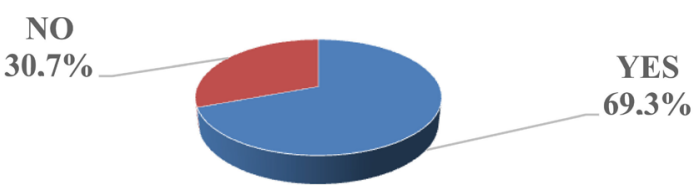

S: only $56 \%$ of the participants declared knowledge of this benefit; This participants $97.70 \%$ informed by doctors about benefit the pulmonary rehabilitation.

Graphic 9. Percentage of research participants with COPD.

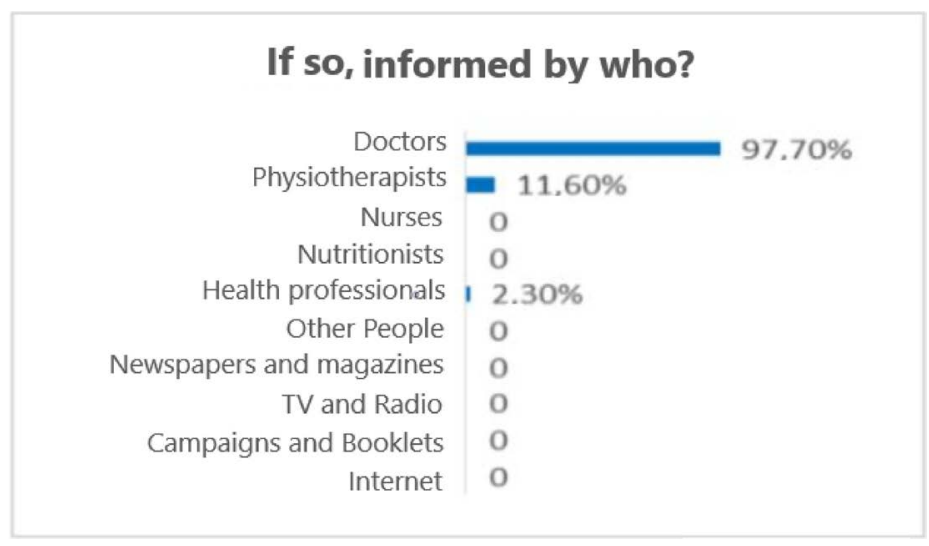

Figure 3. Percentage of the sample about COPD information.

\section{Have you ever accessed the Internet to know about COPD?}

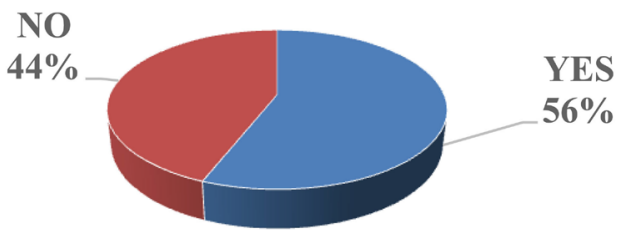

S: the majority $56 \%$ received information when accessed the internet to know about COPD; compared other social media TV and radio 51.70\% receive information according search.

Graphic 10. Percentage of research participants with COPD. 
This reality is already visibly present in social media, where users are motivated to expose their opinions, to participate and share information. It is in this reality of intense mutual collaboration, of unceasing sharing of content, that the area of communication and health has developed.

However, regarding health education offered by the Ministry of Health through its website, our results showed that the minority had knowledge about the page of the Ministry of Health and that they did not use it to obtain information about your health condition. Some participants even showed a lack of interest in accessing the page and others were unaware of this type of information, as shown in Graphic 11.

Educational content is understood as the entire process of constitution of political and social awareness, not television programs that only reproduce teaching formal classroom [27]. Media technologies can be didactic media, depending on the intentions that guide them [28]. Therefore, for health education through social media, it is important to consider the influence of education and the interaction between the three different areas: Communication, Education and Health [27] [28].

According to the data obtained in this study, the most used means of communication for information about the disease and the participants' self-care were

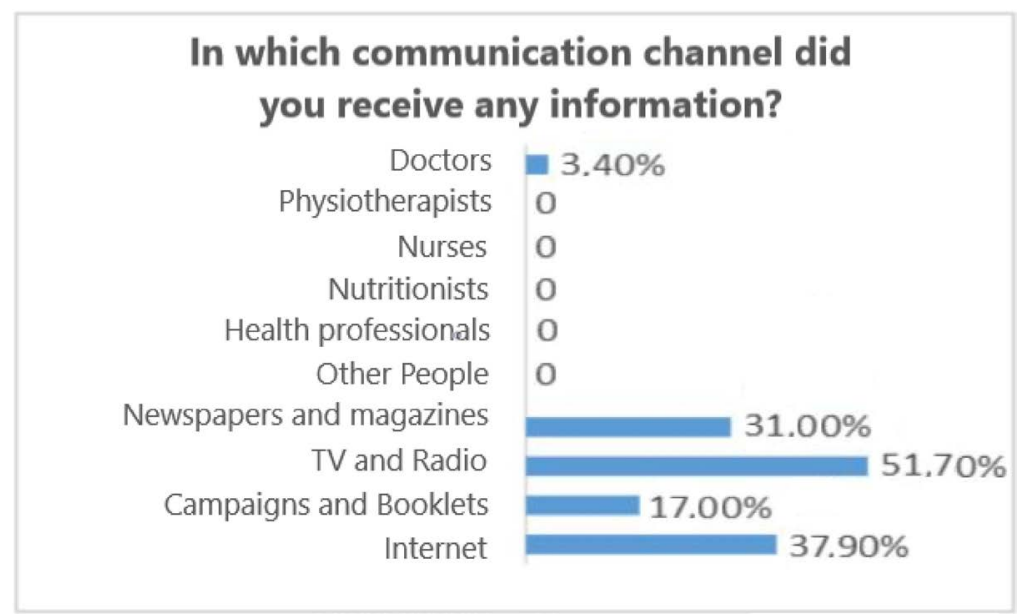

Figure 4. Percentage of the sample about COPD information.

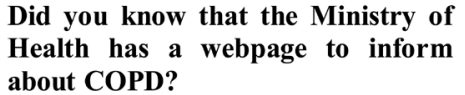

Did you know that the Ministry of Health has a webpage to inform about COPD?

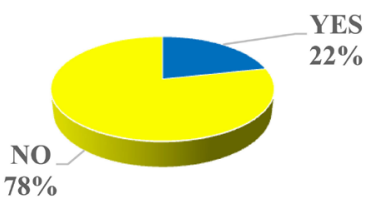

Have you ever accessed the Ministry of Health webpage to get information about COPD?

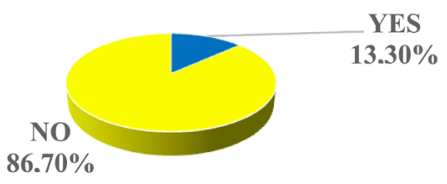

S: The results showed $22 \%$ obtain information in website the Ministry of Health, that did not use information about your health condition; The participants $13.30 \%$ according search have of interest.

Graphic 11. Questions about information of The Ministry of Health webpage. 
magazines, TV, radio and internet. However, at the local level, there are almost no campaigns or reports about COPD, and it is up to the citizen to seek and filter information according to their interest.

According with the studied sample the possible talk to about prevention to reduce the influence of chronic disease if the use to tobacco for the population through educational programs and campaigns against smoking [28].

Based on the studies consulted, the use of cigarettes during adult life over the years develops the disease, followed by exposure to inhalation of chemicals, however, cigarettes have more damage and prevention is believed to play an important role in reducing number of COPD patients [28].

\section{Conclusions}

Along with the studied sample it was possible to conclude that in general, patients diagnosed with COPD, received meaningful information about that pathology, in most cases from their doctors, after that from their physiotherapists. However, relevant subjects as if practice of physical activity, nutrition and pulmonary recovery should be better informed to individuals. Despite the character of Ministry of Health, publishing information about education in health, the majority of the individuals get that important statements directly from their doctors then awareness campaign about the COPD.

The knowledge about the profile and the context of the patients is crucial to determinate and trace strategies about COPD of a systemic picture, thereby, optimizing the treatment and reducing the increased numbers of diagnosis to the disease. For communicational ecosystems, the intertwining of the surrounded systems becomes important to develop more strategies capable of that involve, information, prevention and good communication practices, traced from the dissemination of information about COPD on social media for the knowledge of the population.

\section{Acknowledgements}

The research CAPES, CNPQ and FAPEAM, acknowledgements by financial support for this work. Araújo Lima ambulatory for allowing the research to be carried out. One special thanks to Dr. Socorro Cardoso, by support and contribution for this research. To all patients which collaborated for this result.

Communication Sciences and Health Sciences Master programs and professors, thank you so much, by supporting and developing this master, in special my advisors. My advisor Dr. Roberta Gonçalves Lins for the orientations, patience, help, dedication, competence and support which were essential for my personal and professional growth and finalization of this work. My advisor Dr. Wilson Souza Nogueira for the orientations, patience, comprehension and empathy, besides shared knowledge, they were essential for development of this work.

\section{Conflicts of Interest}

The authors declare no conflicts of interest regarding the publication of this paper. 


\section{References}

[1] Global Initiative for Chronic Obstructive Lung Disease (GOLD) (2019) From the Global Strategy for the Diagnosis, Management and Prevention of COPD. http://www.goldcopd.org

[2] Snider, G.L. (2003) Nosology for Our Day: Its Application to Chronic Obstructive Pulmonary Disease. American Journal of Respiratory and Critical Care Medicine, 167, 678-683. https://doi.org/10.1164/rccm.200203-204PP

[3] Ministry of Health of Brazil (2014) National Health Foundation. DATASUS. Health Information.

[4] Aguiar, A.R.C. (2010) COPD: Multidimensional Assessment of Patients with Chronic Obstructive Pulmonary Disease. Universidade da Beira Interior (UBI).

http://hdl.handle.net/10400.6/742

[5] Lyon, J. (2017) National Plan for COPD Care. JAMA, 317, 2475. https://doi.org/10.1001/jama.2017.7991

[6] Galvez, D.S., Malaguti, C., Battagim, A.M., Nogueira, A. and Velloso, M. (2007) Learning Assessment of Patients with Chronic Obstructive Pulmonary Disease in a Pulmonary Rehabilitation Program. Revista Brasileira de Fisioterapia São Carlos, 11, 311-317. https://doi.org/10.1590/S1413-35552007000400011

[7] Buist, A.S., Mcburnie, M.A., Vollmer, W.M. and Gillespie, S. (2014) International Variation in the Prevalence of COPD (the BOLD Study): A Population-Based Prevalence Study. The Lancet, 370, 741-750. https://doi.org/10.1016/S0140-6736(07)61377-4

[8] Alves, L.C. and Rodrigues, R.N. (2005) Determinants of Self-Perceived Health among Elderly People in the Municipality of São Paulo, Brasil. Revista Panamericana de Salud Pública, 17, 333-341. https://doi.org/10.1590/S1020-49892005000500005

[9] Ministry of Health (2010) Chronic Respiratory Diseases. Health Care Secretariat Department of Primary Care. Série A. Standards and Technical Manuals Primary Care Notebooks, No. 25.

[10] Ibge (2004) Population Projections. Projection of the Population of Brazil: 1980-2050. http://www.ibge.gov.br

[11] Kiley, J.P. and Gibbons, G.H. (2017) COPD National Action Plan Addressing a Public Health Need Together. Chest, 152, 688-699. https://doi.org/10.1016/j.chest.2017.08.1155

[12] Alif, S.M., Dharmage, S.C., Bowatte, G. and Karahalios, A. (2016) Occupational Exposure and Risk of Chronic Obstructive Pulmonary Disease: A Systematic Review and Meta-Analysis. Expert Review of Respiratory Medicine, 10, 861-872. https://doi.org/10.1080/17476348.2016.1190274

[13] Nath, K.D., Burel, J.G., Shankar, V. and Pritchard, A.L. (2014) Clinical Factors Associated with the Humoraimmune Response to Influenza Vaccination in Chronic Obstructive Pulmonary Disease. International Journal of Chronic Obstructive Pulmonary Disease, 9, 51-60. https://doi.org/10.2147/COPD.S53590

[14] Heffner, J.E., Fahy, B., Hilling, L. and Barbieri, C. (2015) Outcomes of Advance Diredive Education of Pulmonary Rehabilitation Patients. American Journal of Respiratory and Critical Care Medicine, 155, 1055-1059.

https://doi.org/10.1164/ajrccm.155.3.9116986

[15] Kopsaftis, Z. and Baker, R.W. (2018) Influenza Vaccine for Chronic Obstructive Pulmonary Disease (COPD). Cochrane Database of Systematic Reviews, 6, CD002733. 
[16] Liu, X.L., Tan, J.Y., Wang, T. and Zhang, Q. (2013) Effectiveness of Home-Based Pulmonary Rehabilitation for Patients with Chronic Obstructive Pulmonary Disease: A Meta-Analysis of Randomized Controlled Trials. Rehabilitation Nursing, 39, 36-59. https://doi.org/10.1002/rnj.112

[17] Devine, E.C. and Pearcy, J. (1996) Meta-Analysis of the Effects of Psychoeducational Care in Adults with Chronic Obstructive Pulmonary Disease. Patient Education and Counseling, 29, 167-178. https://doi.org/10.1016/0738-3991(96)00862-2

[18] Puhan, M.A., Gimeno, S.E., Cates, C.J. and Troosters, T. (2016) Pulmonary Rehabilitation Following Exacerbations of Chronic Obstructive Pulmonary Disease. Cochrane Database of Systematic Reviews, 12, CD005305. https://doi.org/10.1002/14651858.CD005305.pub4

[19] Hakamy, A., Bolton, C.E. and Mckeever, T.M. (2017) The Effect of Pulmonary Rehabilitation on Mortality, Balance, and Risk of Fall in Stable Patients with Chronic Obstructive Pulmonary Disease: A Systematic Review. Chronic Respiratory Disease, 14, 54-62. https://doi.org/10.1177/1479972316661925

[20] Robles, P.G., Brooks, D., Goldstein, R. and Salbach, N. (2014) Gender-Associated Differences in Pulmonary Rehabilitation Outcomes in People with Chronic Obstructive Pulmonary Disease: A Systematic Review. Journal of Cardiopulmonary Rehabilitation and Prevention, 34, 87-97. https://doi.org/10.1097/HCR.0000000000000018

[21] Zhai, T., Li, S., Hu, W. and Li, D. (2018) Potential Micronutrients and Phytochemicals against the Pathogenesis of Chronic Obstructive Pulmonary Disease and Lung Cancer. Nutrients, 10, 813. https://doi.org/10.3390/nu10070813

[22] Moreira, G.L., Manzano, B.M., Gazzoti, M.R. and Nascimento, O.A. (2013) Platino, a Nine-Year Follow-Up Study on COPD in the City of São Paulo: The Problem of Underdiagnosis. The Jornal Brasileiro de Pneumologia, 40, 30-37. https://doi.org/10.1590/S1806-37132014000100005

[23] Stellefson, M., Chaney, B., Ochipa, K. and Chaney, D. (2014) YouTube as a Source of Chronic Obstructive Pulmonary Disease Patient Education: A Social Media Content Analysis. Chronic Respiratory Disease, 11, 61-71. https://doi.org/10.1177/1479972314525058

[24] Lévy, P. (2005) A Plural Globalization. In: de Moraes, D., Ed., For Another Communication-Media, Cultural Globalization and Power, Record, Rio de Janeiro, 91-95.

[25] Jenkins, H. (2008) Convergence Culture. Editora Aleph, São Paulo. https://doi.org/10.1177/1354856507084415

[26] Constituição (1988) Constitution of the Federative Republic of Brazil. Senado Federal: Centro Gráfico, Brasília, 292 p.

[27] ToschI, M. (2002) Media Languages in the Classroom and Teacher Training Teachers. In: Rosa, D.G. and de Souza, V.C., Eds., Didactics and Teaching Practices. Interfaces with Different Knowledge and Training Places, DP\&A, Rio de Janeiro, 265-279.

[28] Liu, X.-L., et al. (2013) Effectiveness of Home-Based Pulmonary Rehabilitation for Patients with Chronic Obstructive Pulmonary Disease: A Meta-Analysis of Randomized Controlled Trials. (C2013 Association of Rehabilitation Nurses Rehabilitation Nursing 2013, 1-24. 